\title{
Haiku as a Transcultural Genre: Trajectories of Crisscrossing Japanese-American Borders
}

\author{
Saeed Gazar*
}

\section{Introduction}

Haiku is a short traditional Japanese poem. It is composed of three unrhymed lines with 17 moras (sound units) or syllables, following mainly the 5/7/5 syllable structure. It often contains a kigo (seasonal reference word), which is selected from a defined list that includes "spring," "leaves" ... etc. (Hakutani 1). When it first appeared in the 13th century, it was the opening part of a renga, an oral poem composed of a hundred stanzas. Yet, the poem broke away as a separate poem in the 17th century (Hakutani 1). It developed into a poetic genre at the hands of the "Great Four," referring to the renowned Japanese poets Basho, Buson, Issa and Shiki. Matsuo Basho (1644-1694) began to write shorter poems known as hokku (now haiku) separately from the renga. His haiku poems are well-known for their direct, simple and natural style, the use of natural imagery in a simple descriptive mood, and the comparison and contrast of two independent phenomena. Since the form used to be viewed as part of other longer poems, it was hard to accept it as an independent medium of artistic expression, and this transformation marks the Basho's achievement (Mackenzie 1957, 5; Hakutani 2009, 9). In fact, haiku has experienced some transitional phases through which it has sometimes been overlooked as mere imitation of Japanese poetics and, in other times, as a genre per se. However, it has withstood all challenges and now "there is a stronger sense of haiku as contemporary poetry, as opposed to an imitative verse form, an exotic hobby, or a spiritual way of life. A wider variety of poetic tools are now recognized as available to the 21 stcentury haiku poet" (Rowland 65).

During the $18^{\text {th }}$ century, the Japanese poet and painter Yosa Buson (17161783 ) continued the work of Basho. His haiku poems, though, are more sensuous and richer in visual detail than Basho's, reflecting his dual career in poetry and

\footnotetext{
* Lecturer in the Department of Foreign Languages, Faculty of Education, Tanta University.

Cairo Studies in English - 2020(2): https://cse.journals.ekb.eg/
} 
painting (Mackenzie 1957, 6). He also urged the use of colloquial language in haiku. In one of his haiku, one reads:

New Year's day!

beyond my thatched cottage

barley fields. (Crowley 2007, 85)

With this approach towards simplicity and the use of day-to-day vocabulary, Buson could add a basic feature to haiku: the form is accessible to the common reader.

Both Basho and Buson had a keen interest in the Japanese landscape. They made long journeys across the Japanese mountains and villages, writing down their observations in poetry and prose (Hakutani 2009, 31). Kobayashi Issa (1763-1828) wrote about 20.000 haiku poems in which he expressed his observations on the calamities of life and portrayed his attentiveness to the small creatures in the world around him. Like Buson, Issa encouraged the liberal use of local dialects and conversational phrases. Because of the personal problems he faced -the death of his first wife and three children, an unsuccessful second marriage, the burning down of his house- his haiku added a melancholic aspect to the genre, taking it a step further towards an understanding of the nuances of human behavior (Addiss 2012, 221-236).

Haiku writing witnessed a major shift in the $19^{\text {th }}$ century as modernization movements were changing most of the world, and Japan was not an exception. In 1868, the Meiji period, characterized by major political and cultural changes, brought about the demise of the feudal system and the start of a modern Japan, following the Western example. One of the loudest voices of this radical change was Masaoka Shiki (1867-1902) the Japanese poet, essayist and critic. He is regarded as the true modernizer of Japanese haiku. As early as 1892, he began to feel that a new literary spirit was needed to free poetry from conventional rules prescribing topics and vocabulary. Therefore, his dedication to haiku modernization is seen as an integral part of the Westernization movement that Japan underwent at the time (Crowley 2007, 167; Hakutani 2009, 13).

Thematically, a haiku is characterized by its directness of expression, focus on natural imagery, simplicity and intensity. The three-line poem juxtaposes two distinctive images taken from the poet's direct experience with nature around him. Essentially, a haiku is better studied as a way of looking at the physical world and conceiving something deeper in it. Basic to this view are issues of the very nature of existence and man's relation to its various phenomena. A haiku 
leaves the reader with a strong feeling or impression resulting from a moment of enlightenment when this reader uncovers some insights because of the juxtaposition of these two images. A typical example of the essence of a haiku is Basho's classic frog poem:

An old pond!

A frog jumps in-

the sound of water. (Addiss 2012, 12)

Basho portrays an image of the old pond vis a vis that of the jumping frog. Detached from any external interpretations, the reader finds that every word bears layers of connotations to comprehend according to his/her view of life. It is the moment when the frog jumps into the pond that triggers the reader's imagination and observation. One may infer from this haiku that nature, which is deeply rooted in history (old pond), is in complete harmony with its elements (frog). Another way of looking at the poem is the eternity of nature which is manifest in the everlasting integration of auditory, visual and kinesthetic aspects of the main elements in the poem: the pond and the frog. One such attempt of understanding Basho's haiku is Daisetsu T. Suzuki's in which he admits that:

[The] sound of water coming out of the old pond was heard by Basho as filling the entire universe." Hearing it, "Basho was no more the old Basho. He was 'resurrected.' He was 'the Sound' or 'the Word' that was even before heaven and earth were separated. He now experienced the mystery of being-becoming and becoming-being. The old pond was no more, nor was the frog a frog. They appeared to him enveloped in the veil of mystery which was no veil of mystery. (qtd in Michael Hoffman, 2019)

Suzuki, a Zen Buddhist, grasps in this haiku the complete harmony of man and nature and the relation that transforms what is apparent to the reader- a frog jumping in the pond- into a transcendental experience of the sublime. In brief, a haiku necessitates the reader to reconsider, reread and ponder over the possible interpretations and insight one may discover in just 17 syllables. This justifies the claim that a haiku presents "[T] he entire universe in 17 syllables!" (Hoffman 2019).

These unique features assist the view that haiku can be dealt with as a transcultural genre. Once Yone Noguchi (1875-1947), the Japanese poet, introduced the form to the rest of the world, many attempts spread over Europe 
in French and English. Notable among such poets are R. H. Blyth, Kenneth Yasuda and Harold Henderson, though some claims suppose that it is Ezra Pound who wrote the first haiku in English: "In a Station of the Metro" published in 1913. Recently, there have been interesting attempts at writing haiku in Arabic. Ezz El-Din Almanasserah, a Palestinian poet, made his first attempts at the genre in the 1960s. Other avant-garde poets, namely Inas Asfari, Ghadeer Hanna and Basem Al-Qassem, to name just a few, have made notable contributions in this respect.

This poses the question as to what makes haiku able to cross cultural barriers. This study, qualitative in nature, explores the features of haiku that help it become a transcultural genre, manifesting the shift in cultural studies from the individualistic specific 'cultura animi' view to the more pluralistic and inclusive one that marks present-day globalized worldview. The study of the haiku written by Masaoka Shiki and the French-Canadian poet Jack Kerouac reveals the existence of such common essential characteristics of haiku. Though they belong to different generations, their haikus are aesthetically linked together, and thus have a strong basis to claim this genre as an epitome of transculturalism.

\section{The Shift from Multiculturalism and Interculturalism to Transculturalism}

Cultural studies have witnessed a shift from the close examination of culture as a reflection of the nation-state domination over its geographical boundaries and ability to keep its unique cultural characteristics. Wolfgang Welsch stresses that this Herderian concept of culture glorifies social homogenization, ethnic consolidation and cultural delimitation. This segregating view does not suit the modern age where the notions of isolation, alienation and homogeneity have led to what Welsch calls the "folk-bound" conception of culture, societies and even individuals. "The classical model of culture," Welsch maintains, "is not only descriptively unserviceable, but also normatively dangerous and untenable" in that it portrays cultures as closed spheres $(2001,59-63)$. The efforts to find an alternative way of dealing with the variety of cultural groups within modern societies have led to multiculturalism and interculturalism. These efforts seek the demolition of any barriers among human societies.

Given the diverse cultural backgrounds in any given society, multiculturalism, in essence, stems from the recognition of all social groups, with their diverse backgrounds. According to this view, social groups of various cultural backgrounds can live peacefully together in any given society. However, this mode has its own drawbacks. It can be the reason for a competition between 
such groups existing side by side within the same geographical boundaries. Each group tries to exercise its power over the other minor groups, reinforcing the dominance of the more powerful culture. Welsch suggests that going multicultural does not overcome the constraints of the traditional concept of culture. It, moreover, provides the proper environment for "ghettoization and cultural fundamentalism" (2001, 65). The cultural, racial or political barriers remain there, hindering the real understanding of this diversity, or even the transgression of such barriers. The same defect can be traced in the case of "interculturalism" which claims cross-cultural dialogue and denies selfsegregation tendencies within cultures. It glorifies diversity, and describes the wide range of communication processes and problems that naturally appear within any social context made up of individuals from different religious, social, ethnic and educational backgrounds. The term denotes an attempt towards peaceful coexistence, understanding and cooperation among cultures. The Council of Europe gives the example of Intercultural Cities Programme to prove the benefits of going intercultural. One benefit is the movement from just the recognition of "other" cultures to "regarding diversity as an asset, and helping them (i.e. Intercultural Cities) to develop policies for advantageous diversity management" (Council of Europe). Yet, interculturalism, in this sense does not affirm the removal of barriers among cultures. It, rather, establishes them firmly in citizens' minds, even within the local milieu of a city. It recognizes the "island or sphere-like constitution of cultures" which "necessarily leads to intercultural conflicts, and attempts to counter these with intercultural dialogue" (Welsch 2001, 66).

The concept of "transculturalism," which can be defined as "seeing oneself in the other," seems to overcome the aforementioned limitations. It is based on the breaking down of boundaries, and glorifies liberation. "It is rooted," Richard Slimbach contends, "in the quest to define shared interests and common values across cultural and national borders" $(2005,206)$. Slimbach equips the transcultural learner with a "cognitive map" that would guide him/her through this transcultural odyssey. Transcultural competence can be cultivated through various techniques whose result can assist individuals to "bring their knowledge of relationships within their own culture to the process of cultivating relationships across cultures.... Our aim is more modest: to cultivate a new way of seeing the world, and thus, of understanding ourselves" $(2005,207)$. This is achievable because, instead of constructing barriers, "we discover the ways that others make sense of their world. In so doing we expand the range of alternative 
mores and manners, values and visions that are available to us for running our lives" $(2005,209)$.

Another positive aspect of the transcultural approach is the fluidity it provides. Globalization has made the transition of people as well as cultural products among world nations much easier, reinforcing the idea that change is the essence of human interaction. Jeff Lewis stresses that the temporal nature of everything is inherent even in cultural affairs. Since culture is formed in language, it is thus marked as "transitory, unstable and dynamic." This makes of culture "a resource for identity liberation, diversity, free imagining, and expressiveness" $(2002,16)$. Transgression of barriers in this case is attainable and gains solid ground over other terms of multicultralism and interculturalism, which do not negate the existence of barriers among cultural groups.

The third benefit of transculturalism is the notion that truth can never be located in one culture or society. There is an urgent need to be open to, and subsequently accept, alterity. Slimbach believes:

The very particularity of our cultural experience is what limits our knowing, and renders the truth contained in our perspectives and positions partial at best. This is why we must enter into the thinking of those shaped by other cultural and political traditions. Only by doing so can we move toward broader knowledge and fuller truth. $(2005,212)$

Transculturalism, as such, marks a change in the view of diversity among people. Cooperation and the desire to complement each other would be the main incentive for a transcultural position. It also allows for cultural experimentation, leading ultimately to cultural development and the birth of what Arianna Dagnino calls "the liquid age" in which citizens become "de-territorialized" $(2013,130)$. This is affirmed by a similar increase in the use of the term "global citizens," stressing the high rate of mobility in the world today.

\section{Haiku as a Transcultural Genre}

In the preface to The Haiku Masters: Four Poetic Diaries, Gail Sher says:

[S]ince the bombings of Hiroshima and Nagasaki, the poetic form known as haiku has moved from the wards and precincts of Japan's old cities to circle our planet. What was once a specifically Japanese 
verse practice...is now the most widely practiced form of poetry in North America, Europe, and possibly worldwide. (2008, ix)

Sher's words give a way to questioning how haiku has attained this global transcultural position. In essence, the genre is based on several aesthetics rarely found in other poetic forms. Its main goal, as Kerouac stresses, is to "see the natural world sharply, refresh our language, and to redirect our focus: 'aiming towards enlightenment'، (qtd in Sher 2008, ix). To achieve enlightenment, a haiku poet focuses on a moment devoid of any background: cultural, political or social. To read a haiku means to be free of any historical bearings, traditional bias and direct associations to specific poetics other than the notion that the human experience of the world is a whole unity. A haiku stresses this freedom from all associations in order to reach the Edenic form of living in and with the universe. It offers, Tom Lynch believes, "the possibility of absolute novelty, of freedom from the past and tradition, of a human potential for absolute beginnings at any time" $(2001,116-17)$. This possibility stems from haiku's dependence on the concise phrasing of an experience, which strikes the reader's attention and calls for deep contemplation. Haiku also requires the reader to depend only on sensual and direct experience of the elements represented in the poem per se, without making any allusions to theories of philosophy or intellectual inferences. Given that, one can discover a new relationship with the world, or at least view difference in this world differently.

This departure from the need to interpret a haiku in light of a certain background helps the reader to move a step further towards believing in universal unity, which is central to haiku writing. Japanese poets had this approach in mind throughout their career, backed by the Zen traditions which denote that "an Edenic escape from preconceptual frameworks" (Lynch 2001, 117 ) is always there for man to discover and enjoy. In his Introduction to Zen Buddhism, Suzuki maintains that "(I)f there is anything Zen strongly emphasizes, it is the attainment of freedom; that is, freedom from all unnatural encumbrances" $(1964,41)$. Man can now think of all animate and inanimate objects as complementary, forming a unity of existence. This very direct experience of the world is where Zen and haiku converge. What Zen, after all, is about is that man's mind must be free (Suzuki 1964, 41). For Suzuki, one has to see the world with naked eyes and touch it with real hands: a condition that is prized by "heavens" that are brought down to earth: 
Zen reveals itself in the most uninteresting and uneventful life of a plain man of the street, recognizing the fact of living in the midst of life as it is lived. Zen systematically trains the mind to see this; it opens a man's eye to the greatest mystery as it is daily and hourly performed; it enlarges the heart to embrace eternity of time and infinity of space in its every palpitation; it makes us live in the world as if walking in the garden of Eden; and all these spiritual feats are accomplished without resorting to any doctrines but by simply asserting in the most direct way the truth that lies in our inner being. $(1964,45)$

Zen, which is central to the haiku experience, directs humans to the path of rediscovering the universe around them. The starting point here is ignorance in the sense that man starts reading haiku with nothing but the state of "not knowing:" a state asserted by Lynch as the sine qua non of haiku composition (2001, 119).

Central to the genre is letting objects express themselves through the objects themselves rather than the poet's personal experience of such objects. The sense of harmony with nature is reflected in every haiku. "A classic haiku," maintains Hakutani, "while it shuns human-centered emotions, thrives on such a naturecentered feeling.... This sensibility cannot be explained by logic or reason. Longer poems are often filled with intellectualized or moralized reasoning, but haiku avoids such language" $(2009,10)$. Being based on direct experience of the world, haiku leaves room for the reader to rethink, reconsider and ponder the possible meanings latent in the three lines, and the poet only lets the objects presented in the poem speak their poetic nature through words.

Another aspect of haiku that adds to its ability to be a transcultural genre is its economy and briefness. Short as it is, a haiku stipulates a moment of enlightenment in the reader's mind. Despite the enigma the reader might feel towards the poem at first, the concise phrasing and order of images urge the reader to stop and contemplate the hidden truth behind these few words. This conciseness and condensation of expression is advantageous in that the reader does not indulge in long narratives that require, in a way or another, allusion to external bearings. Mike Spikes finds a strong correlation between haiku and Ockham's razor principle which appreciates economy in everything. For Ockham, "it is vain to do with more what can be done with fewer" (qtd in Spikes 2013, 64). In haiku, the economy of expression emphasizes the reader's freedom 
to interpret the poem the way he/she pleases, adding more weight to the transcultural effect of the genre.

Yet, this economy of expression is not haphazard. The poet is keen on portraying the two images in a way similar to the cinematic montage where every scene is designed to trigger a specific effect if looked at from certain angles. This effect, naturally, changes with the change of the angle. In haiku, the same technique is there. Owing to the concise phrasing of the three lines, the reader can look at them from any angle and reach any conclusion. With no background whatsoever, any reader can uncover some hidden truth about life and human existence.

Dealing with the genre in Arabic, Bushra Bustani finds that haiku writing depends mainly on "cinematic montage where there are both a structural cut and a connotation link. This cut-link feature of haiku allows the poet to start with the normal then shock the reader with a totally different level of connotation" (Translation mine) $(2015,49)$. In this way, the reader has to immerse him/herself in this very decisive moment, trying to decipher whatever meanings this scene can bear. In this tough mission, the reader will not resort to any traditional inventory of knowledge; what is required is just intuition and interaction with the elements of such a scene. This reading of haiku includes a transition from the personal to the universal and transcultural:

The haiku aesthetics shift from the private self, sect and approach, to the general worldly cosmic issues of the human community. It is a shift from the limited to the comprehensive: saving man from selfisolation through opening the door to all that is communal and universal in front of him. (Bustani, 2015, 51; translation mine)

This resonates with Haruo Shirane's remark that Basho intended his poems to be "a literary text that had to transcend time and place," and is "understood by those who were not at the place of composition...so that the poem would have an impact beyond its original circumstances" $(2000,63)$.

\section{Masaoka Shiki and Jack Kerouac: Transcultural Poets}

Masaoka Shiki (1867-1902) was a poet, author, and literary critic in the second half of $19^{\text {th }}$ century Japan (the Meiji period). He is most notable for his remarkable efforts in revolutionizing, as well as modernizing, haiku, making of it an authoritative poetic genre. Shiki, for Charles Trumbull, was the right person in the right place at the right time. He was born of a samurai family that faced many financial problems. His early years were affected by the death of his father 
when he was only five years old, and his mother insisted on providing him with private tuition. Moving to Tokyo, he attended the Imperial University in 1890. However, he had to drop out because of his interest in haiku and due to his ill health as he caught tuberculosis. For the rest of his life, his suffering continued until his death in 1867 of the same disease. He was keen on expressing his suffering and the contemplations related to the long days and nights he spent on bed in his writings (Addiss 2012, 267-275).

At that time, poetic short forms such as haiku were declining in popularity and regarded as unsuitable for the new Meiji era. Shiki, on the contrary, could defy such an attitude and silence these hostile voices. Influenced by the mainstream spirit of revolution, renovation and reform that characterized that period, Shiki's attempts to do the same to shorter Japanese poems in general, and haiku in particular, were far from being futile. He wrote a long piece on haiku reform called Talks on Haiku from the Otter's Den which was serialized in the Nippon, a Tokyo newspaper. He stressed the importance of using everyday language in haiku. This progressive step towards realism made his poetry instantly impressive. Burton Watson, who introduced Shiki's haiku to the English readership, comments on the role played by Shiki in the development of the genre as:

Shiki succeeded in injecting new life into the form and restoring it as a vehicle for serious artistic expression. Since his time, the writing of haiku has constituted an integral part of the Japanese literary scene, and in recent years the form has been taken up by poets in many other countries and languages as well. $(2003,10)$

Using informal, spoken language, he stressed the need to resort to the traditional roots of Japanese poetry as a standard for defining modern Japanese modes of expression.

Shiki's efforts to revolutionize the genre are, in many ways, synonymous with Jack Kerouac's achievement as a haiku poet. Kerouac is the one who coined the term "Beat Generation" and, as Barbara Louise Ungar mentions, "one of the first dissatisfied writers who discovered the new wealth of the East" (2007, 21). Jack Kerouac was born in 1922 in Lowell, Massachusetts, to French-Canadian parents. He was a serious child who was devoted to his mother, because she was a devout Catholic and instilled in him this deep faith. He joined Colombia University, but soon dropped out and formed, along with Allen Ginsberg and William S. Burroughs, what became The Beat Generation (Theado 2000, 9-12). 
His personal life, full of disappointments, led him to write The Town and the City, a novel about the torments he was suffering as he tried to balance his wild city life with his old-world family values. Shocked by the disparity between materialistic city life in 1950's America and his Buddhist readings, he, following in the footsteps of Japanese haiku poets, made some amazing cross-country trips while working on one of his novels. Worthy of note is his experimentation with freer forms of writing, partly inspired by the unpretentious, spontaneous prose. He decided to write about such trips exactly as they had happened, without pausing to edit, fictionalize or even think (Theado 2000, 31). This marked the birth of Kerouac's style of writing. In April 1951, Kerouac threaded a huge roll of paper into his typewriter and wrote the single 175,000-word paragraph that became On the Road. Published six years later in 1957, the novel made Kerouac instantly famous, giving him the title of a spokesperson for the "Beat Generation," those young people in the 1950s and 1960s who scorned middleclass values. His classic book became the bible of this countercultural generation.

Despite Shiki's and Kerouac's different cultural backgrounds, they share their intense belief in transcultural aesthetics, outlined above. They sought freedom and found in haiku a medium that transcends all cultural boundaries. In the following section, the study will examine how the two poets' visions are reflected in their haiku through the examination of three basic approaches: accepting alterity, shasei and free association.

\section{Accepting Alterity}

The first trajectory through which Shiki's and Kerouac's haiku could cross cultural borders in Japan and the US is their readiness to accept alterity. Alterity is commonly defined as "the Other," denoting difference and diversity. The term has come to be part of many disciplines such as philosophy, theology, ethics, phenomenology, feminist theory, queer theory, hermeneutics, psychoanalysis, psychology and cultural anthropology. However, Emmanuel Levinas' (19061995) definition has a strong affinity to the study of haiku as a transcultural genre. For Levinas:

Alterity is not found in the other bearing additional traits or qualities beyond us, nor as being different by greater or lesser degrees along continua, as these would be constituents of an alter ego and not an other. Alterity as otherness, rather, is always the quality of the other that escapes the self's comprehension, resists possession by the self, refuses to be subsumed into preexisting categories of knowledge or 
consciousness, and is not merely the complementary opposite of a total system with the self. (qtd in Huett and Goodman 2014, 82)

Alterity, according to Levinas, has much to do with negating the self's preeminence as superior to other identities. This allows for a perception of "Other" cultures as having qualities that are valuable in themselves, and thus necessitates demolishing the cultural boundaries that may separate the Self and the Alter. Accepting alterity may be viewed as corollary to political as well as social change. This coincided with the transformations, both political and cultural, which the two poets witnessed. During such periods, the society is directed to ways of reform, wherever they are, particularly if this reform provides an escape from the status quo.

Just as Shiki came in close contact with the Western culture during the Meiji period, which marked the Japanese Westernization process, Kerouac articulated the need for an open mindedness to the wealth of Japanese culture. The latter found in Buddhism and Zen a resort to self-satisfaction, thus the birth of the Beat Generation. Hakutani maintains that during the 1940s, Kerouac "immersed with American transcendentalism, read Emerson, Thoreau and Whitman ... [and] was influenced by Emerson's concept of self-reliance ... stubborn independence and refusal to subscribe to society's materialistic, commercial demands" $(2009,91)$.

Shiki realized the urgency of the Westernization of Japanese poetic forms, including haiku. He lived in a period when complete awareness and openness to the West was necessary. The abolition of feudalism made possible tremendous social and political changes. Millions of people were suddenly free to choose their occupation and move about without restrictions. By providing a new environment of political and financial security, the government made possible investment in new industries and technologies. The most important feature of the Meiji period was Japan's struggle for the recognition of its considerable achievements and for equality with Western nations. Japan was highly successful in organizing an industrial, capitalist state on Western models. In the light of all these transformations, Shiki could present to the world a type of haiku that could survive to this day (Sumikawa).

Similarly, the US had undergone a change in thought during the 1950s, when Kerouac's interest in developing American haiku was at its highest. The period leading up to the 1950s was considered the Era of Conformity. At that time, the majority of Americans were living in suburban areas called Levittowns after Abraham Levitt (Crystal Galyean). Threatened by Communism, they were driven by conspicuous consumption. Men would go to work all dressed up in a 
gray or blue flannel suit while women were domesticated as they stayed home to cook, clean, and tend the children. For Americans at that time eating a family dinner and watching TV every night was considered a conservative tradition. However, this all soon changed post WWII. People were tired of the routine and felt "beaten" down by the traditional lifestyle. ("What is the Beat Generation?") Change was inevitable, and the Beat Generation could effectively achieve it. Experimentation with new literary forms, including haiku, and a total openness to Eastern spiritualism such as Buddhism and Zen were the fruit. Kenneth Rexroth juxtaposes Japanese and American cultures:

Japan became a dream world in the metaphorical sense - a world of exquisite sensibility, elaborate courtesy, self-sacrificing love, and utterly anti-materialist religion, but a dream world in the literal sense, too, a nightside life where the inadequacies and frustrations of the American way of life were overcome, and the repressions were liberated and the distortions were healed. $(1973,151)$

Many of Shiki's haiku give witness to this openness to, and acceptance of, the West as well as the modernization processes under which Japan went. Elements such as "the rail" and "the ship" mark this clearly.

Low over the rail-road,

Wild geese flying;

A moon-lit night. (Blyth 1952, v. 4, 62)

This haiku moment is one of harmony between the wild geese, flying over the modern railroad in a night lit by a natural source (i.e. the moon). Despite the fact that this haiku depicts the supremacy of the natural over the man-made, it highlights the connectedness, if not the mutual harmony, between both. Shiki is not keen on presenting the modern as opposed to the traditional; on the contrary, he keeps an eye on the collaboration of both since they mark $19^{\text {th }}$ century Japan. This is echoed in the following haiku where he observes that:

A lonely

Railway station;

Lotus-flowers blooming. (Blyth 1952, v. 4, 62) 
The representation of the Western railway station and the traditional Japanese lotus-flowers side by side is unique. Shiki stresses the two basic characteristics of this haiku: loneliness and blooming. The blooming of the lotus can be apprehended as an emphasis on the revival of the ancient in times of modernization. The Japanese always boast of this ideal as they never give way to the modern in place of the traditional. The sea, a remarkable element of Japanese geography, marks the same notion:

A great ship

Towing a small boat behind it

Into the haze. (Blyth 1952, v.2, 87)

The ship, which is seen by many as great, towers over the small boat in a view that puts both as complementary elements. To know that both go into the haze may lead the reader to realize how they will soon be invisible or covered by other natural elements in a harmonious liaison. Haiku as a genre has always been linked to the natural world, and Shiki's innovation is in his encompassing both the traditional and the modern inside the haiku natural framework.

Kerouac's openness to the East parallels Shiki's keen interest in the West, influenced by the Confucian thought that the universe consists of heaven, earth, and humans in complete harmony. This sparked the notion of peacefulness in nature in Kerouac's mind, and, one may venture he became dissatisfied with the Western lifestyle that is focused on materialism. In his haiku, he intensifies the need for a worldview that stems from the Eastern (Japanese) culture.

Reflected upsidedown,

In the sunset lake, pines

Pointing to infinity. (Kerouac 2003, 101)

In a moment of deep contemplation, Kerouac grasps this upsidedown nature of life in the modern age. Materialism could not satisfy the soul's needs and infinity could be reached through the return to nature. Pine trees and their reflections in the lake water form a line to infinity: a goal that $20^{\text {th }}$ century people in the West earnestly seek.

Kerouac also celebrates universal integration through maintaining that nature is stable, while the materialistic view of the world changes constantly. He tries to draw the backyard and after a while he observes that it is still the same: 
The backyard I tried to draw

- It still looks

The same. (Kerouac 2003, 117)

This realization of the eternal fixed characteristic of natural elements assists Kerouac's belief in Confucian thought that largely depends on the harmony and stableness of the entire world. Hakutani once again remarks that, like Basho's, Kerouac's haiku glorifies universal integration: "despite the human creation of the space, they (garden/backyard) still belong to the earth, a permanent space under heaven" $(2009,95)$. The same attitude can be found in the following haiku:

The summer chair

Rocking by itself

In the blizzard. (Kerouac 2003, 36)

Even inanimate objects (the chair) react to natural phenomena in an indication that they are part of a global, universal system of which humans are no exception. The "chair" is qualified by "summer" to signify the relatedness to nature. It even has inherent power to move by itself like any other element in this system. Life in all its forms, Kerouac contends, is organic, albeit superficially changeable. Yet, Kerouac is also aware that both the modern (Western) and the traditional (Eastern) must together. Nothing is contradictory between them.

No telegram today

- Only more

Leaves fall. (Kerouac 2003, 5)

This haiku depicts someone waiting for a telegram, which may be a usual habit. At the same time, this person still observes the falling of more tree leaves on earth. The juxtaposition of the telegram and the leaves provides enough room to incorporate both in one frame. Here lies the greatness of haiku as a genre that is capable of lasting and crossing any borders.

\section{Shasei: Fact over Fiction}

The other main strategy through which haiku could transgress American borders is the ideology of shasei. It originally means "sketch from life," and has much to do with realism and the insistence to depict things as they are in real life. This could grant haiku a characteristic peculiar to this genre since it negates imagination and gives the reader a solid ground to stand on throughout ages and 
geographical milieus. Shasei is itself trans-cultural: it is related to Western schools of painting. Trumbull's search for the origin of the term led him to Watson's commentary on Shiki's resort to it. Watson sees that the poet borrowed the term from the vocabulary of Western painting because "the writer was to carry out minute observation of the scenes around him and to compose works based on what he saw there, conjuring up the mood or emotional tenor he desired through apt manipulation of the images found in real life" (Trumbull n.d., n. pag.). The reason for Shiki's admiration of shasei is what he read in Herbert Spencer's On Style in which he argues that a good writing style has to depend on clarity and lucidity. This aspect has greatly influenced Japanese writers in general, and Shiki in particular. John Ruskin's idea that the representation of facts must be the foundation of all art was the other source from which Shiki derived the basic concept of shasei (Trumbull n.d., n. pag.).

Lee Gurga maintains that Shiki's contribution to the development of shasei can be traced through three hierarchical stages: sketch from life, selective realism and poetic truth. The poet moves forward through these stages in order to attain truth, which is the core of haiku:

Shiki did, in fact, support the use of imagination in haiku, but proposed that poets attempt to use it only after they had developed a sufficiently fine perception of the world and experience of truth. Only then could they be trusted to attempt to convey their personal vision to the reader through the distillation of imagination. Shiki's suggested development of the poet - from "sketches of life" for the beginner to "selective realism" for the more advanced poet to makoto or "poetic truth" for the master is as valid today as it was one hundred years ago when he proposed it. $(2000,60)$

According to Peter Lamarque $(2014,121-23)$, poetic truth denotes several meanings, prominent among which are seriousness, sincerity and absence of fault. The poet tries hard to attain poetic truth through sincerity to nature as it is. Everything depends on both the poet's and the reader's direct experience of the two images in a haiku. Reaching the moment of enlightenment, which is a tough mission, requires the reader to be serious and sincere to the objects per se, rather than what these objects may connote. Haiku masters, such as Basho, were keen on highlighting this goal: attaining makoto, or truth in poetic art. Gurga assures that the reason behind haiku transgression of cultural borders is its dependence on realism, or shasei. This stems from the poet's essential fidelity to Nature rather 
than empty imagination. That is why when English speaking poets, Kerouac is an example, came in contact with Japanese writing, they at once adhered to its aesthetics and propagated them in their work. Trumbull has good reasons to claim that most American haiku are merely shasei haiku.

Shiki seeks makoto in his haiku. He urges the reader to stop and value the silence before, within and after the words where one thinks deeply until reaching a moment of enlightenment. Here lies haiku's major benefit. In the following haiku, for example, he is not only sketching the image of blossoming pears, but he also directs the reader's attention to the destroyed house after a battle.

the pear blossoming

after the battle this

ruined house. (Blyth 1952, v.1, 66)

Ideas of rebirth and the resourcefulness of nature are present in this haiku. The aesthetic of "fact over fiction" permeates haiku and makes of it a transcultural genre. The reader is left free to infer other ideas and get deeper into the haiku. For instance, in cultures that have suffered from the effect of wars, this haiku will instill the horrible effect of battles in the minds. Others may find in it a hope that every battle has an end. On a third vein, spiritually speaking, the ruined house may refer to the catastrophic impact of materialism in general, and capitalism in particular. There is an urgent need for a spiritual renewal of the human psyche. The same applies to a haiku like the following:

looking down I see, cool in the moonlight, 4000 houses. (Beichman 1982, 51)

Here, the reader realizes that the speaker is on a higher place than the houses. A feeling of ecstasy may ensue when the moonlight covers the 4000 houses beneath. Shiki presents his readers with a realistic image with loads of deeper meanings.

Referring back to Trumbull's comment that American haiku is shasei haiku, it is evident in Kerouac's work that capturing realistic snapshots of nature is one reason for its greatness as well as its uniqueness. Addressing a bee, he says:

Bee, why are you

staring at me?

I'm not a flower! (Kerouac 2003, 15) 
Kerouac affirms the beneficiary relationship among all living things. Here, from the bee's perspective, a flower is the source of nectar, and man is supposed to be its enemy rather than the source of nourishment. Yet, the question mark may urge the reader to pause, think and review the relation with natural elements. Through shasei, the representation of life as it is and the search for truthfulness rather than truthiness (i.e. superficial incorrect view of life) assists the reader on the journey to attain satori (comfort and peace of mind) (Hakutani 2009, 81). Kerouac celebrates this state in many haiku:

Quietly pouring coffee

In the afternoon, How pleasant! (Kerouac 2003, 47)

The tranquility one enjoys in the heart of nature, away from the madding crowd in city life is the apprehension one finds in this haiku. Hakutani reports that Kerouac lived in close contact with nature throughout his career (99). Attaining satori, the poet, and the reader in return, will have the chance to get wiser and realize the integration of everything in this world:

In my medicine cabinet

The winter fly

Has died of old age. (Kerouac 2003, 12)

Medicine, which does not help the fly to live longer, will not help humans either: another fact over fiction case.

\section{Free Association}

Inherent in haiku writing is its reliance for the most part on free association. The genre eschews logical or theoretical backgrounds for its understanding. Richard Iadonisi highlights this resistance to "New Critical craft" which depends on "rational means of composition" $(2014,292)$. All haiku take free association as a point of departure; the poet takes a snapshot of whatever he/she observes, frames it under whatever background and leaves the rest to the reader. No meaning is definite for any haiku, but the deep thinking of the wordiness, so to speak, will guide the reader in a process of free association. Thinking of haiku as a transcultural genre, this element is basic in this respect. Haiku could transgress American as well as European borders through this space of freedom 
that the reader enjoys in inferring whatever meanings and arranging them in any order. An example of this is Kerouac's icebox haiku:

Missing a kick

At the icebox door

It closes anyway. ((Kerouac 2003, 16)

Human limitation, universal power and system are mere examples of the sheer association of ideas that may come to the mind from the first reading of this haiku. Other layers of associated ideas can be thought of according to the reader's perception and background. For instance, Iadonisi finds in it a proof of Kerouac's negligence of the feminine, making of haiku a masculine form of art $(2014,295)$. Shiki also urges the use of conversational everyday language in order to allow this stream of associations. His poems are marked by a kind of flexibility that allows him to draw upon scenes in his memory. In the following haiku, the contradiction between presence and absence triggers a battle in the reader's mind with no victorious part:

Always someone resting there --

a lone rock

in the summer field. (Watson 1997, 65)

The eternal presence of "someone" is contrasted with the "lone rock." In a sense, this evokes a stream of associations related to this unknown person who "always" rests there. At the same time, ideas related to the reason for resting there, and the identity of this place will open up the door to an endless process of stream of consciousness. The seasonal term "summer" plays its role in evoking notions of heat, aridity and loneliness. Yet, the "lone rock" has been in company with others all the time. Now, it suffers the agony of being forsaken by people. This may also relate to ideas of the man-nature dichotomy in the mind.

\section{Conclusion}

This study provides a close examination of the various strategies and trajectories through which haiku, the Japanese poetic form, could cross American borders. Shiki's contribution to the modernization of the genre, emphasizing the importance of fact over fiction (shasei), assists in the liberation process a haiku reader undergoes. Adhering to the Zen traditions of sincerity to nature and the use of everyday language frees the reader of any cultural background, and permits the free association of ideas of any type. The 
achievement of Shiki's efforts can be clearly seen in the introduction of the genre to Americans in the middle of the twentieth century. The work of Kerouac, one of the Beat Generation founders, is a true representation of the same trajectories taken by Shiki. Both poets depend on the genre's brevity, condensation and strict form in their writing. The genre could also be transcultural through accepting alterity, shasei and free association. As such, the study opens the door for more studies of haiku in other languages, especially Arabic, which, despite its complexities, has adopted the genre.

\section{Works Cited}

Addiss, Stephen. 2012. The Art of Haiku: Its History Through Poems and Paintings by Japanese Masters. Colorado: Shambhala.

Beichman, Janine. 1982. Masaoka Shiki. Boston: Twayne Publishers.

Blyth, R. H. 1952. Haiku. V. 1-4. Tokyo: Hokuseido.

Bustani, Bushra. 2015. "Arabic Haiku: Structure and Visions." Rasail Shir (Poetry Letters Magazine), no. 3 (July): 47-54. www.poetryletters.com Council of Europe. 2020. "Interculturality" Intercultural Cities Programme $<$ https://www.coe.int/en/web/interculturalcities/interculturality $>$.

Crowley, Cheryl A. 2007. Haikai Poet Yosa Buson and the Basho Revival. Leiden: Brill.

Dagnino, Arianna. 2013. "Global Mobility, Transcultural Literature, and Multiple Modes of Modernity." Transcultural Studies, no 2. (December): 130-160.

Galyean, Crystal. "Levittown: The Imperfect Rise of the American Suburbs." $<$ https://ushistoryscene.com/article/levittown/>.

Gurga, Lee. 2000. "Toward an Aesthetic for English-Language Haiku," Modern Haiku vol. 31, no.3 (Fall): 59-73.

http://www.baymoon.com/ ariadne/form/haiku/haiku.aesthetics.gurga.htm

Hakutani, Yoshinobu. 2009. Haiku and Modernist Poetics. New York: Palgrave Macmillan.

Hoffman, Michael. 2019. "Be a Frog and Jump into Basho's Pond." $<$ https://www.japantimes.co.jp/news/2019/10/19/national/history/frog-jumpbashos-pond/\#.XuT1p0UzbIV>.

Huett, Steven and David Goodman. 2014. "Alterity." Encyclopedia of Critical Psychology. Ed.: Thomas Teo,. Springer, New York, NY.

Iadonisi, Richard A. 2014. "The Masculine Urge of Jack Kerouac's Haiku," The Journal of American Culture. vol. 37, no. 3 (September): 290-98. 
Kerouac, Jack. 2003. Book of Haikus. New York: Penguin.

Lamarque, Peter. 2014. The Opacity of Narrative. London: Rowman \& Littlefield International.

Lewis, Jeff. 2002. "From Culturalism to Transculturalism." Iowa Journal of Cultural Studies, no. 1 (Spring):14-32.

Lomas, Tim. 2016. "The Art of Second Wave Positive Psychology: Harnessing Zen Aesthetics to Explore the Dialectics of Flourishing." International Journal of Wellbeing, vol. 6, no. 2: 14-29.

https://doi.org/10.5502/ijw.v6i2.497

Lynch, Tom. 2001. "Intersecting Influences in American Haiku." In Modernity in East-West Literary Criticism: New Readings edited by Yoshinobu Hakutani, 114-136. London: Madison.

Mackenzie, Lewis. 1957. The Autumn Wind: A Selection from the Poems of Issa. London: John Murray.

Rexroth, Kenneth. 1973. "The Influence of Classical Japanese Poetry." In The Elastic Retort, 149-57. New York: Seabury Press..

Rowland, Philip. 2013. "New Directions in English-language Haiku: An Overview and Assessment." The IAFOR Journal of Literature and Librarianship vol. 2, no. 2 (Autumn): 53-66.

Sher, Gail. 2008. The Haiku Masters: Four Poetic Diaries. California: Night Crane Press.

Shirane, Haruo. 2000. "Beyond the Haiku Moment: Basho, Buson, and Modern Haiku Myths." Modern Haiku vol. 21, no. 1: 48-63.

Slimbach, Richard. 2005. "The Transcultural Journey." Frontiers: The Interdisciplinary Journal of Study Abroad. vol. XI (August): 205-230.

Spikes, Mike. 2013. "Haiku and Ockham's Razor: The Example of Jack Kerouac." Modern Haiku. vol. 44, no. 2: 58- 66.

Sumikawa, Shunsuke. 1999. "The Meiji Restoration: The Roots of Modern Japan." Lehigh University.www.lehigh.edu> courses > spring > Papers > pdf > shs3

Suzuki, Daistez T. 1964. An Introduction to Zen Buddhism. New York: Grove Atlantic.

Theado, Matt. 2000. Understanding Kerouac. South Carolina: University of South Carolina Press.

Trumbull, Charles. N.D. "Masaoka Shiki and the Origins of Shasei." $<$ https://www.thehaikufoundation.org/juxta/juxta-2-1/masaoka-shiki-andthe-origins-of-shasei/>. 
Ungar, Barbara Louise. 2007. "Haiku in English." Simply Haiku, vol. 5, no 4 (Winter): 21-33

Watson, Burton. 1997. Masaoka Shiki; Selected Poems. New York: Columbia University Press.

Watson, Burton. 2003. For All My Walking: Free Verse Haiku of Taneda Santoka. Columbia: Columbia University Press.

Welsch, Wolfgang. 2001. "Transcutlurality: The changing form of cultures today." Letnik. vol. 22, no. 2: 59-86.

"What is the Beat Generation?" AP Comp: The Beat Generation. $<$ https://sites.google.com/site/ahsapcompthebeatgeneration/home/what-isthe-beat-generation $>$. 